\title{
Antitumor compounds from Streptomyces sp. KML-2, isolated from Khewra salt mines, Pakistan
}

Usman Aftab ${ }^{1,2^{*}}$, David L. Zechel ${ }^{2}$ and Imran Sajid ${ }^{1}$

\begin{abstract}
Background: Actinomycetes are gram positive bacteria with high $\mathrm{G}+\mathrm{C}$ content in their DNA and are capable of producing variety of secondary metabolites. Many of these metabolites possess different biological activities and have the potential to be developed as therapeutic agents. The aim of the present study was to screen actinomycetes inhabiting halophilic environment such as Khewra salt mines present in Pakistan for cytotoxic and antitumor compounds.
\end{abstract}

Results: An actiomycetes strain designated as Streptomyces sp. KML-2 was isolated from a saline soil of Khewra salt mines, Pakistan. The strain Streptomyces sp. KML-2 showed $84 \%$ cytotoxic activity against larvae of Artemia salina. In the screening phase, the strain exhibited significant antitumor activity with $I_{50}$ values of 12,48 and $56 \mu \mathrm{g} / \mathrm{ml}$ against Hela, MDBK and Vero cell lines, respectively. After that extract from 20 I fermentation was used to purify secondary metabolites by several chromatographic techniques. Structure elucidation of isolated compounds revealed that it is highly stable producer of Chromomycin SA (1) and 1-(1H-indol-3-yl)-propane-1,2,3-triol (2). Both of the isolated compounds showed significant antitumor activity against Hela and MCF-7 cancer cell lines ( $\left(C_{50}\right.$ values 8.9 and $7.8 \mu \mathrm{g} /$ $\mathrm{ml}$ against Hela; 12.6 and $0.97 \mathrm{\mu g} / \mathrm{ml}$ against MCF-7, respectively). The $16 \mathrm{~S} \mathrm{rRNA}$ gene sequence (1437 bp) of the strain confirm its identity (99\%) with Streptomyces griseus.

Conclusions: From this research work we were successful in isolating two potent antitumor compounds, Chromomycin SA and 1-(1H-indol-3-yl)-propane-1,2,3-triol from Streptomyces KML-2 strain, isolated from Khewra salt mine. As such this is the second report which confirms that $S$. griseus can produce Chromomycin SA without introducing any mutagenesis in its biosynthesizing gene cluster and isolated indole derivative is being reported first time from any member of actinomycetes group with having novel antitumor activity against Hela and MCF-7 cells.

Nucleotide sequences: Nucleotide sequence data reported are available in the GenBank database under the accession number: GenBank KJ009562.

Keywords: Streptomyces sp. KML-2, Antitumor activity, Chromomycin SA, 1-(1H-indol-3-yl)-propane-1,2,3-triol

\section{Background}

Nature is an attractive source of new therapeutic compounds, as it represents a pool of secondary metabolites with tremendous chemical diversity. Currently about $60 \%$ of the approved therapeutic drugs are derived from natural sources. These sources include various animals,

\footnotetext{
*Correspondence: usmanaftab.mmg@gmail.com

1 Department of Microbiology and Molecular Genetics, University of the

Punjab, Quaid-e-Azam Campus, Lahore 54590, Pakistan

Full list of author information is available at the end of the article
}

plants, marine-organisms, and microorganisms [1, 2]. Among the different microbial sources, actinomycetes specifically are famous as producers of great number of unique and chemically diverse bioactive compounds. Actinomycetes are filamentous, gram-positive, spore forming bacteria [3]. Members of the class actinomycetes are reported for the production of about 10,000 bioactive compounds among the total 23,000 bioactive secondary metabolites produced by microorganisms, representing 
$43 \%$ of all bioactive microbial metabolites that have been discovered [4].

Actinomycetes are also known as a rich source of potent antitumor compounds. Regardless of the presence of several therapeutic methods for the cancer treatment, cancer is still a major public health threat [5]. Chemotherapy is one of the effective treatments for controlling cancer, but this approach needs a continuous supply of new antitumor compounds. Fortunately, one of the family members of actinomycetes known as Streptomyces helps us by providing promising antitumor compounds, which are unmatched and unrivaled in terms of treatment of cancer. The famous antitumor compounds produced by Streptomyces species and are being used in human chemotherapy includes actinomycin, mitomycin, anthracycline, bleomycin, aureolic acid families, pentostatin and resistomycin [6, 7]. Several studies confirm that Streptomyces are able to produce different antitumor compounds with diverse chemical backbones because they harbor different gene clusters encoding polyketide and nonribosomal peptide synthases [8]. Most of these compounds are secreted in the culture media and can be extracted using organic solvents [9]. There are many diverse mechanisms by which these compounds are able to control different tumor cells which includes apoptosis, mitochondrial permeabilization, blockage of signal transduction pathways by inhibiting key enzymes, cytomorphological changes due to disturbance in cellular differentiations, and tumor induced angiogenesis [10]. Sometime antitumor compounds isolated from Streptomyces strains act by intercalating with duplex DNA, which leads to detrimental effects on fast proliferating cells by inhibiting the DNAdependent RNA polymerase activities [11].

In order to establish a unique pool of Streptomyces strains that can be examined for new anticancer drugs, we focused on gathering strains from unique habitats and conducting target directed biological screening [12, 13]. Among different habitats, normal terrestrial habitat is the most explored one, while there are very few studies conducted on extreme ecological niches, like forests, salt stress areas, hills, desert etc. [14]. Our aim from both of these strategies is to attain novelty in biological activities and chemical structures.

To this end, the present study reports the isolation of a Streptomyces strain, KML-2, from the Khewra salt mines in Pakistan. Culture extracts from KML-2 exhibited potent cytotoxic activity against Artemia s. larvae and antiproliferative activity against three cell lines. These activities inspired us to isolate the bioactive molecules and determine their structures and bioactivities. Phylogenetic analysis was performed by conducting ribotyping studies of the strain KML-2.

\section{Results and discussion} Isolation and taxonomic characteristics of Streptomyces sp. KML-2

In order to meet the increasing demand for the treatment of human illness, new biologically active metabolites are needed. In this battle microorganisms are generally, and in particular actinomycetes, are prominent producers of chemically diverse compounds with multiple activities. However after several decades of extensive screening it has become difficult to simultaneously find novel compounds and novel microorganisms. Despite of this fact, there are some unique ecological niches in the world which are unexplored and could be a source of novelty, both for the microorganisms and their compounds. In our case we selected a unique and untapped source for the isolation of actinomycetes, the Khewra salt mine, which is the world's second largest salt mine, located in the province Punjab, Pakistan [15]. Recently few studies report the isolation of novel actinomycetes strains from salt rich environments [16-18].

Several soil samples were collected from the mine and plated on the selective media after making suitable dilutions. After incubation actinomycetes strains were isolated and purified on GYM agar. The strain KML-2 exhibited typical Streptomycetes like characteristics (Table 1). Individual colonies grew well in an elevated manner with red vegetative mycelia and yellow aerial mycelia. As depicted in the scanning electron microscope image, the spore chains were straight, smooth, thick, and branched with very little coiling. The diameters of the spores are constant with having connection to substrate mycelia (Fig. 1a-d). All of the morphological and surface parameters observed under scanning electron microscope are in close similarity with family known as Streptomycetaceae and the genus Streptomyces.

The comparison of biochemical, physiological and microscopic characteristics (Table 1) with those of known actinomycetes species mentioned in Bergey's Manual of Systematic Bacteriology strongly suggested that the strain KML-2 belongs to the genus Streptomyces [19]. It can utilized D-galactose, D-glucose, mannose, glycerol and mannitol as a carbon source indicating its ability to grow on variety of sugars. The strain tested negative in biochemical tests like hemolysis and melanin production. Out of several organic acids tested for utilization, the strain KML-2 utilized only potassium gluconate and trisodium citrate (Table 1).

Several molecular techniques are being used in the research for investigating the evolutionary relationship among isolated microorganisms. By the help of these kinds of molecular techniques we can easily verify the hypothesis generated from other characterization 
Table 1 Taxonomic characteristics of the Streptomyces sp. KML-2

\begin{tabular}{|c|c|}
\hline & Observed results \\
\hline \multicolumn{2}{|l|}{ Morphological parameters } \\
\hline Aerial mycelium & Detachable/pale yellow \\
\hline Substrate mycelium & Abundant/red \\
\hline Diffusible pigments & Nil \\
\hline Fragmentation pattern of substrate mycelium & Fair \\
\hline Spores & Abundant/smooth \\
\hline Size of colony & $3 \mathrm{~mm}$ \\
\hline Consistency & Hard/embedded \\
\hline Odour & Earthy \\
\hline Elevation & Raised \\
\hline Margins & Entire \\
\hline Surface & Rough \\
\hline Growth pattern & Well growth/partitioned \\
\hline Shape/form & Circular \\
\hline Optical feature & Opaque \\
\hline Gram stain & Positive \\
\hline Motility & Nil \\
\hline Melanin production & - \\
\hline Urease & ++ \\
\hline Hemolysis & - \\
\hline \multicolumn{2}{|l|}{ Utilization of sugars } \\
\hline Glucose & + \\
\hline Fructose & - \\
\hline Arabinose & - \\
\hline Galactose & + \\
\hline Raffinose & - \\
\hline Mannitol & + \\
\hline Sucrose & - \\
\hline Mannose & + \\
\hline \multicolumn{2}{|l|}{ Utilization of organic acids } \\
\hline Potassium gluconate & + \\
\hline Trisodium citrate & + \\
\hline Sodium malate & - \\
\hline Sodium lactate & - \\
\hline Sodium malonate & - \\
\hline Oxalate & - \\
\hline
\end{tabular}

+ , positive; - , negative; ++ , strong positive methods like physiological and biochemical tests [20]. Among all the techniques ribotyping is very commonly used one, in which $16 \mathrm{~S}$ rRNA gene sequence data of the isolated strain is compared with the sequence data present in the Genbank database. In our case we are able to sequence total nucleotide of $1437 \mathrm{bp}$ (Accession No: KJ009562) of the 16S rRNA gene of Streptomyces sp. KML-2. The BLAST analysis was performed by aligning this sequence with the $16 \mathrm{~S}$ rRNA gene sequences present in the Genbank database. Blast results exhibited highest similarity ( $99 \%$ similarity) with the $16 \mathrm{~S}$ rRNA gene of Streptomyces griseus (Fig. 2).

\section{Cytotoxicity and antitumor activity of Streptomyces sp. \\ KML-2}

A significant challenge in isolating bioactive compounds from microorganisms is having an appropriate and sensitive bioassay to guide the purification process [21]. In our case we screened extracts from Streptomyces sp. KML-2 using several bioassays in order to exploit its full chemical potential. We started with measuring the cytotoxic effects of the crude extract of this strain against the larvae of Artemia s. commonly known as brine shrimp [22]. The cytotoxic profile of the crude extract from Streptomyces sp. KML-2 showed very promising results. This strain produces compounds which have the ability to inhibit $84 \%$ of the growth of Atremia s. larvae. The high cytotoxic response against Artimia s. suggests that the extract of this strain might contain some potent antitumor compounds. We then selected the MTT assay to test the antitumor activity of this strain against Hela cells (cervical cancer) and two normal cell lines including MDBK (cow kidney epithelial cells) and Vero cells (African green monkey kidney epithelial cells). We observed differential antitumor activity against tested cell lines in a dose-dependent manner. The survival rate of Vero and MDBK cells is higher compared to Hela cells. $\mathrm{IC}_{50}$ values for Hela, MDBK and Vero cells were 12.17, 47.88 and $56.12 \mu \mathrm{g} / \mathrm{ml}$ respectively. Such differential behavior with several normal and cancer cell lines including Hela were observed for the extracts and pure compounds isolated
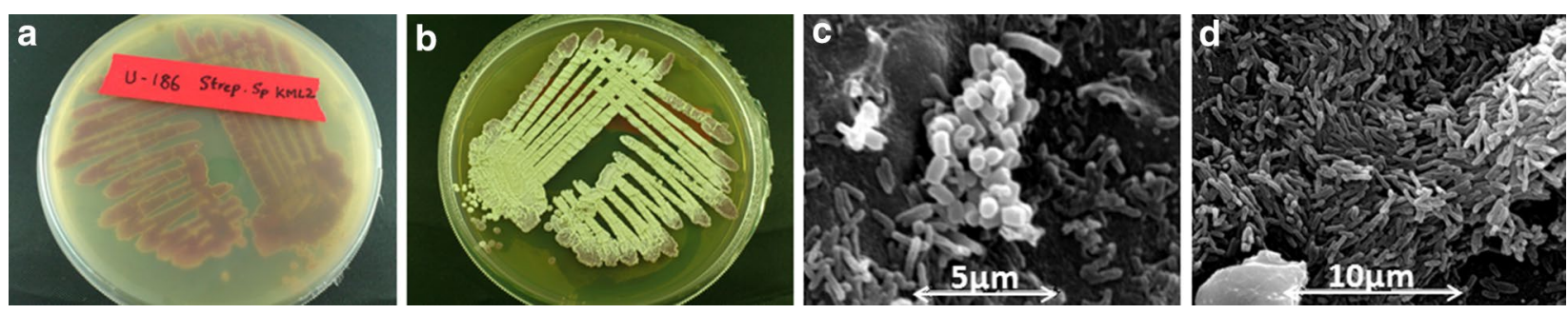

Fig. 1 a, b Substrate and Aerial mycelia of Streptomyces sp. KML-2; c, d scanning electron microscope images of Streptomyces sp. KML-2 


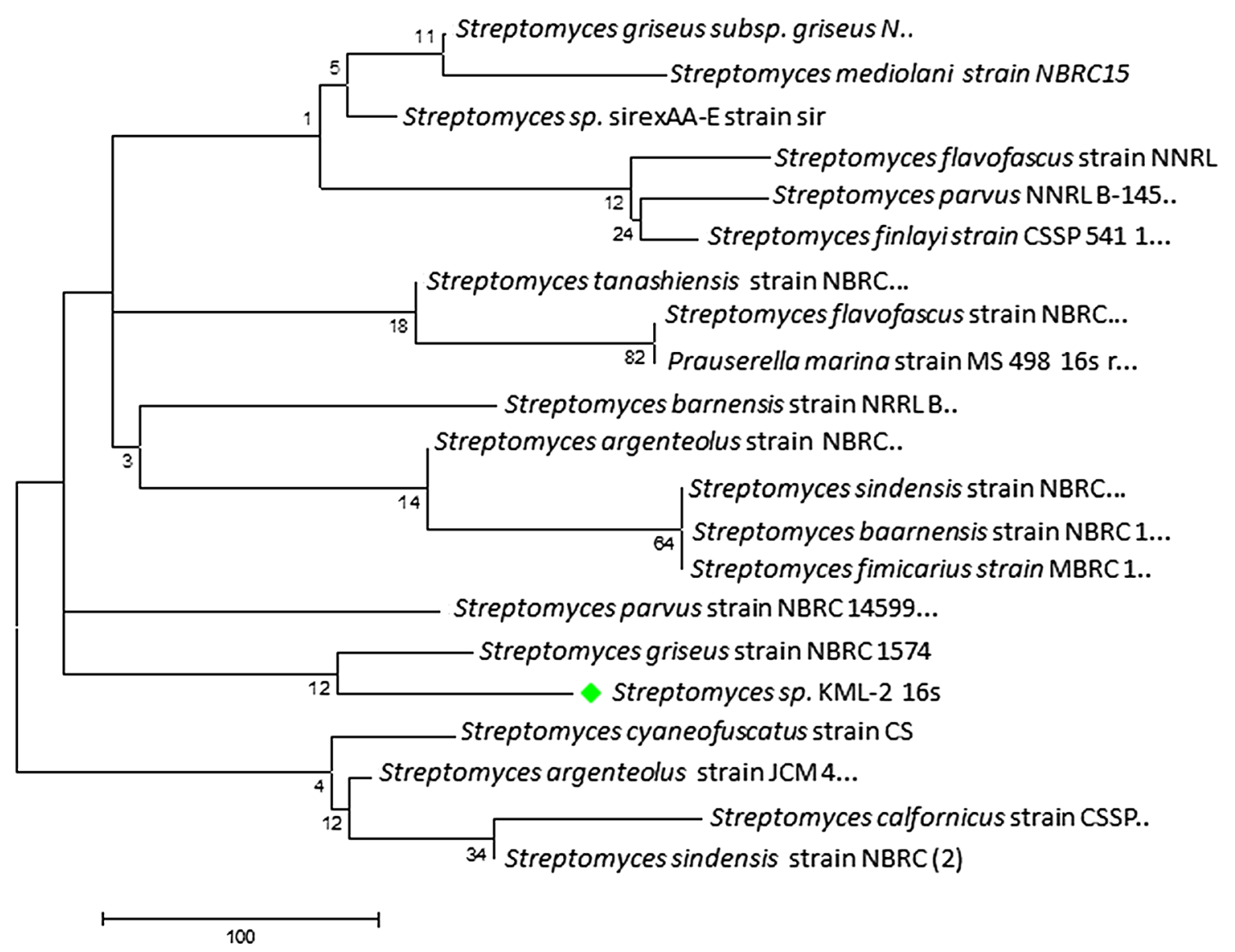

Fig. 2 Phylogenetic tree of Streptomyces sp. KML-2

from different Streptomyces species in several studies [23-27]. These data indicate that the MTT assay utilized in our study is suitable for screening antitumor agents with high cytotoxic activities. No significant antibacterial activity was seen when the extracts was screened against the general panel of gram positive and gram negative bacteria.

Later on after isolation and purification, the antitumor activity of two pure culprit compounds was also evaluated by using MTT assay. Initially antitumor potential of the compound 1 and 2 was checked against Hela and MCF-7 (breast cancer) cell lines. It is observed that both compounds showed significant antitumor activity against both cell lines with $\mathrm{IC}_{50}$ value of 8.9 and $7.8 \mu \mathrm{g} / \mathrm{ml}$ against Hela cells respectively. Activity of compound 1 against MCF-7 is also significant with having $\mathrm{IC}_{50}$ value of $12.6 \mu \mathrm{g} / \mathrm{ml}$, but compound 2, which was found novel in terms of source and activity after performing structure elucidation experiments, shows marvelous antitumor potential against MCF-7 cells with having $\mathrm{IC}_{50}$ value of only $0.97 \mu \mathrm{g} / \mathrm{ml}$ (Fig. 3).

\section{Purification and structure elucidation of the antitumor metabolites}

The 201 shaking flasks culture of the isolate Streptomyces sp. KLM-2 was extracted using Diaion HP-20 beads and $1.5 \mathrm{~g}$ red color crude extract was obtained. Two different compounds were separated by preparative TLC. The compound 1 is yellow in color with $\lambda_{\max }$ at 437, 317 and $280 \mathrm{~nm}$. After that this pure compound was analyzed on UPLC/MS system and $m / z$ ratio of $1125.47[\mathrm{M}+\mathrm{H}]^{+}$was observed in positive ES mode. This value, along with the distinct absorbance spectrum is consistent with already reported compound named as Chromomycin SA having Chemical formula: $\mathrm{C}_{54} \mathrm{H}_{76} \mathrm{O}_{25}$, Exact mass: 1124.47, Molecular weight: 1125.17, Elemental analysis: C, 57.64; $\mathrm{H}, 6.81$; O 35.55 (Figs. 4a, 5a). Results of ${ }^{1} \mathrm{H}$-NMR experiment for this isolated compound confirmed its identity as Chromomycin SA (Additional file 1: Table S1). Chromomycin SA is a yellow color compound produced by Streptomyces griseus, already reported for a potent activity against Hela cells [23]. Our phylogenetic, morphological and physiological analysis also confirm that our strain have 99 \% similarity with S. griseus. Chromomycin SA 

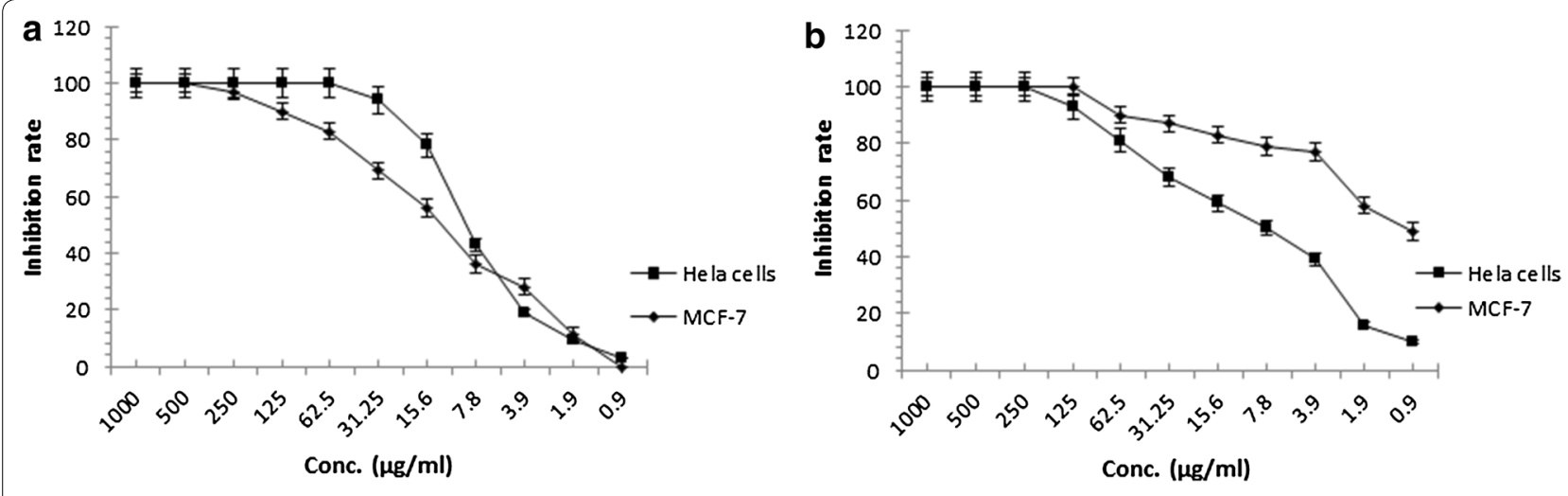

Fig. 3 Activity of Compound 1 (a) and Compound 2 (b) against Hela and MCF-7 cell lines

belongs to the class of polyketide compounds known as aureolic acids. Aureolic acid family contains potent antitumor compounds which inhibit the replication and transcription process during macromolecules biosynthesis. They also interact with the minor groove of DNA in GCrich region. This binding is non-intercalative in nature, via cross linking of DNA in the presence of $\mathrm{Mg}^{2+}$ [28].

Previously Menéndez et al. [23] reported isolation of Chromomycin SA from a S. griseus strain that has been genetically altered specifically through the inactivation of ketoreductase gene $(\mathrm{cmmW1})$. Later on $\mathrm{Hu}$ et al. [29] reports the isolation of Chromomycin SA without introducing any mutation in ketoreductase gene. They proposed that Chromomycin SA is byproduct in nature, formed during the synthesis of different analogs of Chromomycin SA. They have isolated the S. griseus strain from saline environment which is also similar in our case. So we can hypothesized that might be there is some relation between inactivation of ketoreductase gene and stress acclimatization. Latest studies have also introduced the new term known as ecovars, in which strains of $S$. griseus might be undergoing ecology-specific evolution, which results in the genetic variation with the specific ecology [30].

Compound 2 with $m / z 208[\mathrm{M}+\mathrm{H}]^{+}$was purified by column chromatography over silica gel with the Methanol: Dichloromethane solvent gradient system and Sephadex LH-20 column. After purification $6 \mathrm{mg}$ of pure compound was obtained. Structure of this pure compound was determined through Bruker Avance $600 \mathrm{MHz}$ NMR spectrometer. After performing several two dimensional NMR experiments compound 2 was identified as 1-(1H-indol-3-yl) propane- 1, 2, 3-triol (Fig. 4b), one of the derivative of indolic compounds (Additional file 1: Table S2) with Chemical formula: $\mathrm{C}_{11} \mathrm{H}_{13} \mathrm{NO}_{3}$, Exact mass: 207.09, Molecular weight: 207.23, Elemental analysis: $\mathrm{C}, 63.76 ; \mathrm{H}, 6.32 ; \mathrm{N}, 6.76 ; \mathrm{O}, 23.16$. To the best of our knowledge this type of indolic derivative has not been reported earlier from Streptomyces source, however one study depicted its isolation from clavicipitaceous fungi Balansia epichloe (B. epichloë) with high toxicity against fertile chicken eggs [31]. Earlier only fungus is reported among natural sources for the production of this type indolic derivative but now some studies also reports its chemical synthesis [32]. Several actinomycetes strains were reported for the presence of tryptophan metabolism gene clusters, which are responsible for the production of different indolic derivatives [33]. As shown in Fig. 4b 1-(1H-indol-3-yl)-propane-1,2,3-triol has $\lambda_{\max }$ at 227 and $279 \mathrm{~nm}$, which is very common among different derivatives of indoles which are reported for having promising antitumor activity against several different tumor cell lines [34].

\section{Conclusion}

From this research work we were successful in isolating two potent antitumor compounds from Streptomyces KML-2 strain. From the results we can inferred that the strain Streptomyces KML-2 is potent source of antitumor agents. This study also reveals that Khewra salt mine from where the strain KML-2 was isolated is a potent ecological niche with having inimitable strain diversity which are yet to be discovered. In short these unique habitats should be continuously explored for extracting lead antitumor compound. Furthermore we will try to check the activity of isolated compounds against different cancers including colorectal and liver cancers, which are present in very high intensity worldwide and specifically in Pakistan.

\section{Methods}

\section{Sample collection and enrichment}

Soil samples were collected from Khewra salt mines, Punjab, Pakistan, in sterile sampling bag, from the depth 


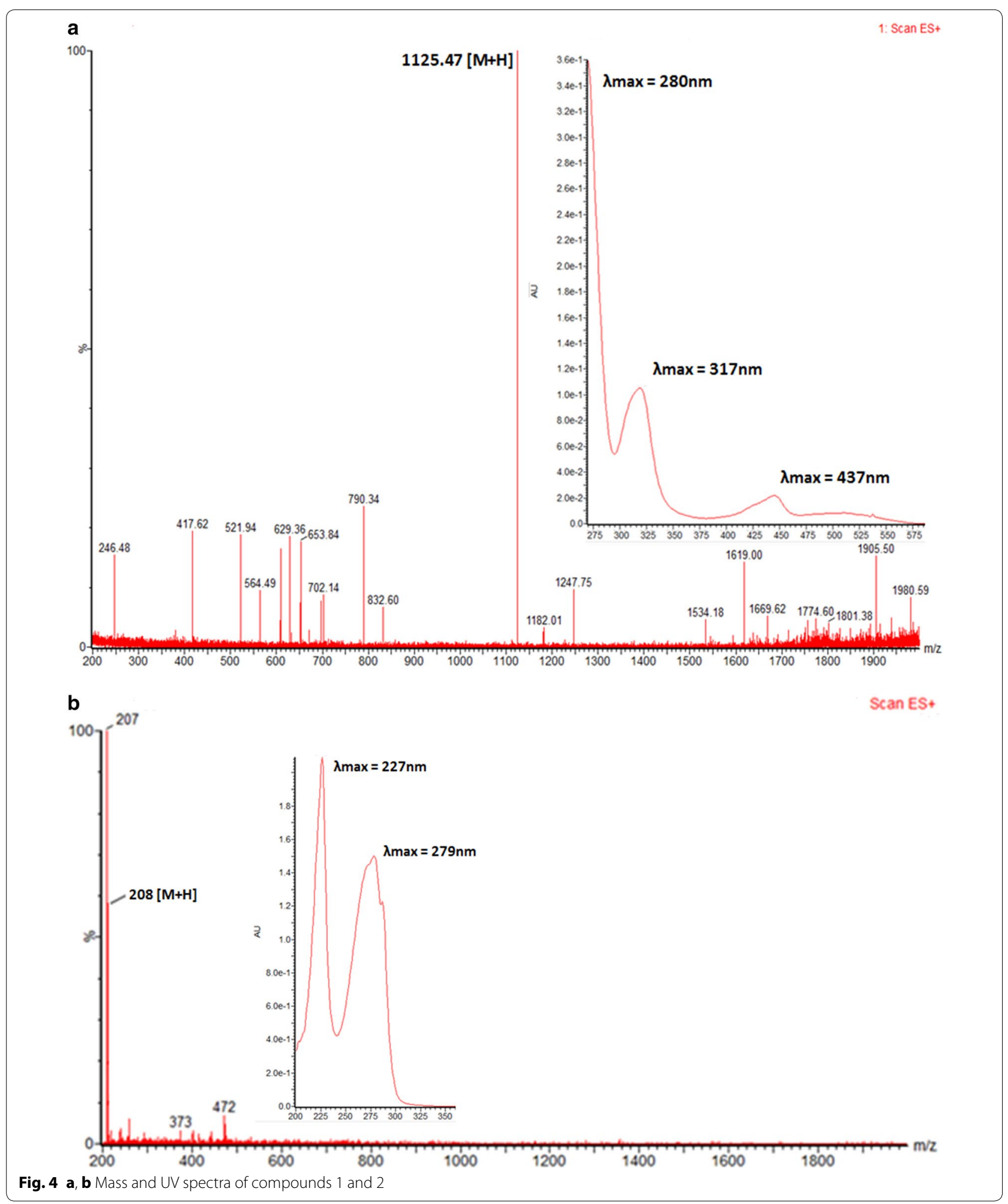

of 5-10 cm, quantity of each of the collected sample was between 2 and $5 \mathrm{~g}$. The samples were then treated using different physical and chemical methods for the enrichment of actinomycetes. In physical treatment the samples were kept at high temperature $\left(55^{\circ} \mathrm{C}\right)$ for $2-3$ weeks and in chemical treatment soil samples were 


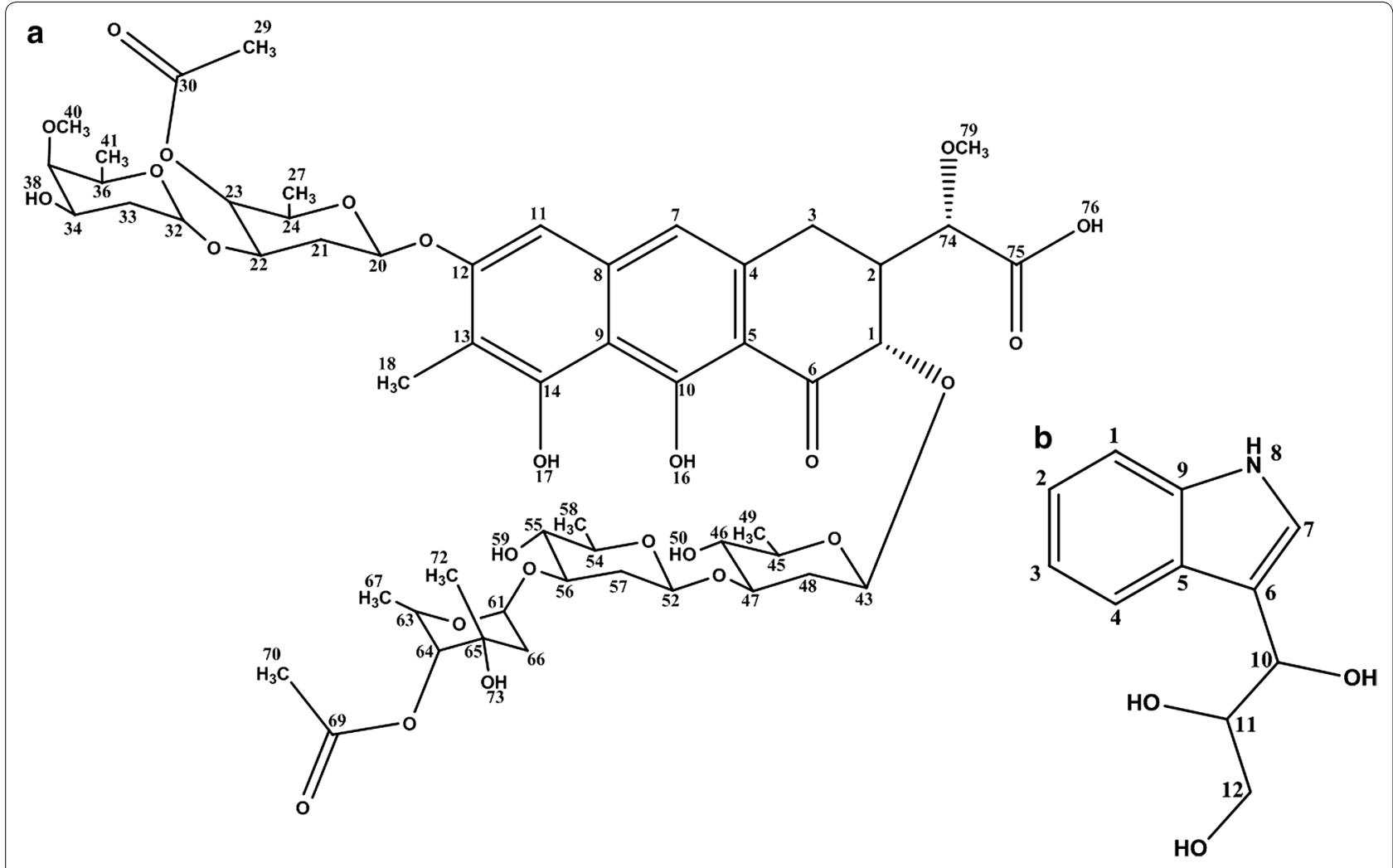

Fig. 5 a, b Molecular Structure of Chromomycin SA (Compound 1) and 1-(1H-indol-3-yl) propane- 1, 2, 3-triol (Compound 2)

mixed with $\mathrm{CaCO}_{3}$ at the ratio of $10: 1$ and were incubated under moisture rich conditions for 7 days at room temperature [35].

\section{Selective isolation of actinomycetes}

Actinomycetes strains were isolated using selective isolation media Glycerol-Casein- $\mathrm{KNO}_{3}$ agar (glycerol $10 \mathrm{~g}$, $\mathrm{KNO}_{3} 2 \mathrm{~g}$, casein $0.3 \mathrm{~g}, \mathrm{NaCl} 2 \mathrm{~g}, \mathrm{~K}_{2} \mathrm{HPO}_{4} 2 \mathrm{~g}, \mathrm{MgSO}_{4}{ }^{-}$ $7 \mathrm{H}_{2} \mathrm{O} 0.05 \mathrm{~g}, \mathrm{CaCO}_{3} 0.02 \mathrm{~g}, \mathrm{FeSO}_{4}-7 \mathrm{H}_{2} \mathrm{O} 0.01 \mathrm{~g}$, agar $18 \mathrm{~g}$, all in $1 \mathrm{l})$ containing cycloheximide $(50 \mu \mathrm{g} / \mathrm{ml})$ as antifungal agent [36]. About $1 \mathrm{~g}$ of soil was dissolved in autoclaved distilled water and serial dilutions $\left(10^{-2}\right.$ to $10^{-4}$ ) were plated on Glycerol-Casein- $\mathrm{KNO}_{3}$ agar. The plates were incubated for $7-21$ days at $28^{\circ} \mathrm{C}$. The actinomycetes colonies were selected and purified by repeated sub-culturing on GYM agar (10 g malt extract, $5 \mathrm{~g}$ yeast extract, $5 \mathrm{~g}$ glucose, $15 \mathrm{~g}$ agar, all in $1 \mathrm{l}$ of tap water) [37]. Later the selected isolates were preserved in liquid nitrogen for future use.

\section{Morphological, biochemical and physiological characterization of the isolated strain}

The morphologic, biochemical and physiological characteristics of the isolate KML-2 were studied by the methods employed in International Streptomyces Project
(ISP), including colony size, consistency, shape, elevation, margins, color of aerial/substrate mycelium, pigments diffusing into the medium, formation of melanin, utilization of different sugars as sole source of carbon, utilization of organic acids, hemolysis, utilization of oxalates, optimum $\mathrm{pH}$, temperature, aeration, media composition [37, 38].

\section{Scanning electron microscopy (SEM)}

In order to see the deep morphological pattern (substrate \& aerial mycelia) of strain KLM-2, scanning electron microscopy was performed [39]. The strain was grown on GYM agar and a piece of agar containing sufficient growth of the strain was cut with sterile scalpel. The strain was fixed with glutaraldehyde $(2 \%)$ and formaldehyde (5\%), and then incubated at $4{ }^{\circ} \mathrm{C}$ for overnight in $0.1 \mathrm{M}$ sodium cacodylate buffer $(0.1 \mathrm{M}$ cacodylate, $0.01 \mathrm{M} \mathrm{CaCl}_{2}, 0.01 \mathrm{M} \mathrm{MgCl}_{2}, 0.09 \mathrm{M}$ sucrose; $\mathrm{pH}$ 6.9). After overnight fixation, the strain was washed with fresh cacodylate buffer. The strain was then dehydrated with a series of acetone solutions (10, 30, 50, 70, 90, and $100 \%$ acetone). After acetone dehydration, the agar piece containing growth was subjected to critical-point drying with liquid $\mathrm{CO}_{2}$. Before loading the agar piece in the scanning electron microscope (SEM) it was covered with 
a $10 \mathrm{~nm}$ thick gold film by sputter coating (Hummer-V Sputter Coater). After coating, deep morphological patterns of the substrate mycelia of strain KML-2 were analyzed by using scanning electron microscope (HITACHI S-2300 SEM at Electron microscopy facility, Queens University, Canada).

\section{S rRNA gene sequencing}

Total genomic DNA was isolated after growing the stain in GYM broth. Genomic DNA was extracted by the phenol/chloroform method as described by Hopwood et al. [40]. The $1.5 \mathrm{~kb} 16 \mathrm{~S}$ rDNA fragment was amplified by PCR using the universal primers 27F, 5'-AGAGTTTGATCCTGGCTCAG-3' and 1522R, 5'-AAGGAGGTGATCCARCCGCA- $3^{\prime}$. Each PCR reaction vial contained approximately $300 \mathrm{ng}$ genomic DNA, $2 \mu \mathrm{l}$ of each primer having working concentration of $10 \mathrm{pmol}$, and $25 \mu \mathrm{l}$ of 2X PCR master Mix (Merck-GeNei ${ }^{\mathrm{TM}}$ ). The reaction was cycled as follows: $94{ }^{\circ} \mathrm{C}$ for $5 \mathrm{~min} ; 30$ cycles of $94{ }^{\circ} \mathrm{C}$ for $20 \mathrm{~s} ; 50{ }^{\circ} \mathrm{C}$ for $20 \mathrm{~s} ; 72{ }^{\circ} \mathrm{C}$ for $2 \mathrm{~min}$; followed by $72{ }^{\circ} \mathrm{C}$ for $5 \mathrm{~min}$. After amplification, the reaction product was resolved by agarose gel electrophoresis and gel purified using a MiniElute ${ }^{\mathrm{TM}}$ PCR purification kit (Qiagen, USA). The gene product was sequenced using dye terminator chemistry on an automated sequencer (ABI-PRISM ${ }^{\circledR}$ BigDye $^{\circledR}$ Terminator version 3.1 Cycle Sequencing Kit, Applied Biosystems, USA), and the sequence data was compared to existing sequences by BLAST analysis (http://www.nih.nlm.gov/blast.cgi). After analyzing BLAST results, phylogenetic and molecular evolutionary analysis were conducted using software $M E G A$ (version 4) [41]. The sequence was then deposited to the NCBI GenBank.

\section{Small scale cultivation of strain KML-2}

The Streptomyces strain KML-2 was grown in $250 \mathrm{ml}$ GYM broth in 11 Erlenmeyer flasks (the $\mathrm{pH}$ was adjusted to 7.8 before sterilization). The flasks were then incubated at $28{ }^{\circ} \mathrm{C}$ at $100 \mathrm{rpm}$ for $5-7$ days. After incubation the cells were disrupted by sonication. The resulting broth was mixed with ethyl acetate $1: 1$. The mixture was sonicated again and the upper organic layer of ethyl acetate was collected in a separatory funnel. The organic layer was evaporated on rotary vacuum evaporator (Heidolph ${ }^{\circledR}$ 4000 efficient) and a small amount of crude extract was obtained. The crude extract was analyzed for cytotoxic and antitumor activities against different cell lines.

\section{Determination of cytotoxic and antibacterial activity of Streptomyces sp. KML-2}

A microwell cytotoxicity assay as described by Solis et al. [42] was used to check the cytotoxicity of the crude extract against brine shrimp larvae (Artemia s.). In order to calculate the mortality of the larvae, dried eggs of Artemia s. $(0.5 \mathrm{~g})$ were added to a $500 \mathrm{ml}$ separating funnel filled with $400 \mathrm{ml}$ of artificial seawater and were incubated at room temperature for $48 \mathrm{~h}$ under extensive aeration. After incubation the whole suspension was kept undisturbed for $1 \mathrm{~h}$ in order to allow the eggs to settle down. Active larvae were collected by exposing one side of the extraction funnel with light source. About 30-40 active larvae were transferred to the wells of microtiter plate (wells diameter $1.8 \mathrm{~cm}$, depth $2 \mathrm{~cm}$ ) already filled with $0.2 \mathrm{ml}$ of salt water. Dead larvae were counted (value $\mathrm{N})$ before adding $20 \mu \mathrm{g}$ of the crude extract in $5 \mu \mathrm{l}$ of DMSO. The plate was kept at room temperature in the dark. After $24 \mathrm{~h}$, the number of the dead larvae (value A) in each well was counted under the microscope. In order to calculate total number of larvae (value G) all of surviving larvae were killed by the addition of $0.5 \mathrm{ml}$ methanol. The test was performed in triplicate; each test row was accompanied by a blind sample containing pure DMSO as negative control. Actinomycin-D $(10 \mu \mathrm{g} / \mathrm{ml})$ was used as a positive control with $100 \%$ mortality rate. Mortality rate was calculated by using the following formula:

$$
\mathrm{M}=[(\mathrm{A}-\mathrm{B}-\mathrm{N}) /(\mathrm{G}-\mathrm{N})] \times 100
$$

where, $M=$ Percent of the dead larvae after $24 \mathrm{~h}$, $\mathrm{A}=$ Number of the dead larvae after $24 \mathrm{~h}, \mathrm{~B}=$ Average number of the dead larvae in the blind samples after $24 \mathrm{~h}$, $\mathrm{N}=$ Number of the dead larvae before starting of the test, $\mathrm{G}=$ Total number of larvae.

Antimicrobial activity of the extract obtained from the culture broth of Streptomyces sp. KML-2 was determined by disc diffusion method as described by Sajid et al. [43] against a set of test organisms including Bacillus subtilus, E. coli (ATCC 25922), Staphylococcus aureus (ATCC 25923), Methicilin resistant Staphylococcus aureus (MRSA), Acinetobacter, Pseudomonas aeruginosa and klebsiella pneumonia (ATCC 706003).

\section{In-vitro screening for antitumor activity}

The antitumor assay was performed on Hela, MDBK, Vero and MCF-7 cell lines (ATCC) using MTT assay [44]. The cells were grown in 96 well plate in Dulbecco's modified Eagle's medium (Invitrogen, NY, USA) supplemented with $10 \%$ fetal bovine serum and $1 \%$ antibiotics (streptomycin and penicillin-G) by incubating at $37^{\circ} \mathrm{C}$ for $24 \mathrm{~h}$ in $5 \% \mathrm{CO}_{2}$ (Sanyo $\mathrm{CO}_{2}$ incubator MCO-15AC) under humid conditions. After the formation of confluent monolayer of the actively dividing cells, trypsinization was done and cell suspension $\left(10^{5}\right.$ cells $\left./ \mathrm{ml}\right)$ was then seeded in the wells containing culture media and different concentrations of the extract obtained from the shaking culture of KML-2 strain. Plate was then incubated at $37^{\circ} \mathrm{C}$ for $48 \mathrm{~h}$ in $5 \% \mathrm{CO}_{2}$ environment. After incubation 
cellular viability for each concentration of the extract was measured as described by Mosmann, where in $20 \mu \mathrm{l}$ of MTT $(5 \mathrm{mg} / \mathrm{ml})$ was added to each well and the plate was again incubated at $37{ }^{\circ} \mathrm{C}$ for $3 \mathrm{~h}$ in $5 \% \mathrm{CO}_{2}$ environment. After incubation the media was carefully removed and $100 \mu \mathrm{l}$ of DMSO was added in order to solubilize the formazan crystals produced by metabolically active cells. The optical density (O.D) of the wells were then measured with a microplate reader (Epoch BIOTEK ${ }^{\circledR}$ ) at $570 \mathrm{~nm}$ with $655 \mathrm{~nm}$ as reference wavelength. Cellular images were taken through inverted microscope (LABOMED iVu3000-TCM400). Assay controls were maintained throughout the experiment and the assay was performed in triplicates. Calculations of $\mathrm{IC}_{50}$ were done through dose dependent curve. The growth inhibition rate for each dilution was calculated by the following formula:

$$
\begin{aligned}
& \text { Inhibition rate } \\
& \qquad=\frac{\text { O.D }(\text { control well })-\text { O.D (treated well })}{\text { O.D }(\text { control well })} \times 100
\end{aligned}
$$

\section{Fermentation and extraction}

A starter culture was prepared by inoculating $25 \mathrm{ml} \mathrm{GYM}$ broth with the strain KML-2 and incubating at $28{ }^{\circ} \mathrm{C}$ for 4 days at $95 \mathrm{rpm}$. Fermentation was done in ten 51 EM baffled flasks containing springs and glass beads. Each flask contained 21 GYM broth for a total working volume of $20 \mathrm{l}$. Antifoaming agent 204 (Sigma Aldrich), $100 \mu \mathrm{l} / \mathrm{l}$, and $2 \%(\mathrm{v} / \mathrm{v})$ inoculum was added to each flask. The cultures were incubated at $28^{\circ} \mathrm{C}$ for 7 days at $95 \mathrm{rpm}$. After 7 days the culture broth was harvested by centrifugation at $11,000 \mathrm{rpm}$ for $5 \mathrm{~min}$ at ambient temperature. After centrifugation, the liquid phase was separated and Diaion ${ }^{\circledR}$ HP-20 beads (Sapelca analytical USA), prewashed three times with acetone and air dried overnight, were added at a ratio of $10 \mathrm{~g} / \mathrm{l}$. This mixture was incubated for $3 \mathrm{~h}$ on a rotary shaker at $100 \mathrm{rpm}$, and then separated by vacuum filtration. The beads were washed with water 2-3 times followed by three times washing with acetone. The acetone was removed under vacuum to dryness. The solid phase or cellular mass was also extracted three times with ethyl acetate and the solvent was evaporated under vacuum to dryness.

\section{Purification and structure elucidation by UPLC-MS and NMR analysis}

The combined crude extract (extract from liquid as well as solid phase) was fractionated on silica gel column $(25 \times 5 \mathrm{~cm}$, Silica gel 60 , Merck). The fractions were purified by repeated silica gel column chromatography and preparative TLC (PTLC) with a mobile phase of $\mathrm{CH}_{2} \mathrm{Cl}_{2} /$ $\mathrm{MeOH}$ gradient. Final finishing of the purified compounds was done by passing the fractions through Sephadex LH-20 column. The structures of the purified compounds were analyzed through UPLC-mass spectrometry and NMR spectroscopy. The data obtained was compared with reference data present in databases including: Dictionary of Natural Products (DNP), Pub Chem, Scifinder and Chemical abstracts. Compound 1 and 2 were isolated and characterized by UPLC-MS and NMR spectroscopy. For UPLC-MS analysis samples were prepared carefully by dissolving the powder compound in $500 \mu \mathrm{l}$ methanol. Furthermore this methanolic compound mixture was five times diluted in $50 \%$ acetonitrile. The diluted samples were then filtered through $2 \mu \mathrm{m}$ pore size disposable syringe filters and further centrifuged at 14,000 rpm in order to remove any particle. Samples were then transferred to special LC-MS glass vials which were further placed in the sample tray of UPLC-MS machine. The analytical conditions for the UPLC-MS analysis were as follows: Waters ACQUITY UPLC H-class BEH-C18, $(2.1 \times 100 \mathrm{~mm}$; particle size, $1.7 \mu \mathrm{m}$ ) column; Column temperature: Ambient; Gradient Elution: A is Acetonitrile, B is Acetonitrile $+0.5 \%$ acetic acid, $C$ is MilliQ water $+0.5 \%$ acetic acid, D is MilliQ water; Gradient Profile: $0-1.5$ min $5 \%$ B and $95 \% \mathrm{C}, 1.5-7 \mathrm{~min}$ is $95 \% \mathrm{~B}$ and $5 \% \mathrm{C}, 7-10 \mathrm{~min} 95 \%$ $\mathrm{B}$ and $5 \% \mathrm{C}$, Before and after run column was re-equilibrate by eluting with $100 \% \mathrm{~A}$ and B; Flow rate: $0.5 \mathrm{ml} / \mathrm{min}$; $\mathrm{m} / \mathrm{z}$ monitoring range $200-2000 \mathrm{~m} / \mathrm{z}$ ratio; Wavelength monitoring range $220-800 \mathrm{~nm}$; Total run time: $10 \mathrm{~min}$; Data: Continuum; Seal wash period: $5 \mathrm{~min}$; Waters SQ detector mass spectrometer; Ionization mode: ESI positive; Scan Duration: $0.5 \mathrm{~s}$; Capillary voltage, $3.3 \mathrm{kV}$; Cone voltage ramp: on; Source temperature: $150{ }^{\circ} \mathrm{C}$; Desolvation temperature: $400{ }^{\circ} \mathrm{C}$; Desolvation gas flow: $800 \mathrm{l} / \mathrm{h}$; Cone voltage; $0 \mathrm{~V}$; Desolvation gas: liquid nitrogen; Mass lynx software V 4.1 (waters).

Structure of the compounds were elucidate on Bruker Avance $600 \mathrm{MHz}$ NMR machine by using simple 1D and 2D NMR spectroscopic techniques for ${ }^{1} \mathrm{H}$ - and ${ }^{13} \mathrm{C}$. Several techniques including COSY, HMBC, HSQC and NOESY were also performed for the correct structure elucidation in the 2D NMR spectroscopic analysis.

\section{Additional file}

Additional file 1. Table S1: NMR correlation table of compound 1. Table S2: NMR correlation table of compound 2.

\section{Authors' contributions}

UA carried out the whole research studies, including cell culturing experiments and drafted the manuscript. DZ participated in the Mass and NMR spectrometric analysis. IS participated in the design of the study and performed the statistical analysis. All authors read and approved the final manuscript. 


\section{Author details}

${ }^{1}$ Department of Microbiology and Molecular Genetics, University of the Punjab, Quaid-e-Azam Campus, Lahore 54590, Pakistan. ${ }^{2}$ Department of Chemistry, Queens University, Kingston, ON K7L 3N6, Canada.

\section{Acknowledgements}

We are thankful to Higher Education Commission (HEC) Pakistan for financial support under IRSIP Scholarship Program for the completion of this research work. We are also thankful to Dr. Françoise Sauriol for her help regarding NMR experiments and XiMing Zhu for mass spectrometry analysis.

\section{Competing interest}

The authors declare that they have no competing interests.

Received: 25 August 2015 Accepted: 29 September 2015 Published online: 14 October 2015

\section{References}

1. Cragg GM, Newman DJ, Snader KM. Natural products in drug discovery and development. J Nat Prod. 1997;60(1):52-60.

2. Newman DJ, Cragg GM, Snader KM. Natural products as sources of new drugs over the period 1981-2002. J Nat Prod. 2003;66(7):1022-37.

3. Ventura M, Canchaya C, Tauch A, Chandra G, Fitzgerald GF, Chater KF, et al. Genomics of actinobacteria: tracing the evolutionary history of an ancient phylum. Microbiol Mol Biol Rev. 2007;71(3):495-548.

4. Berdy J. Bioactive microbial metabolites. J Antibiot. 2005;58(1):1-26.

5. Parkin DM. Global cancer statistics in the year 2000. Lancet Oncol. 2001:2(9):533-43.

6. da Rocha AB, Lopes RM, Schwartsmann G. Natural products in anticancer therapy. Curr Opin Pharmacol. 2001;1(4):364-9.

7. Newman DJ, Cragg GM. The discovery of anticancer drugs from natural sources. Nat Prod. Springer; 2005. p. 129-68.

8. Ayuso A, Clark D, González I, Salazar O, Anderson A, Genilloud O. A novel actinomycete strain de-replication approach based on the diversity of polyketide synthase and nonribosomal peptide synthetase biosynthetic pathways. Appl Microbiol Biotechnol. 2005;67(6):795-806.

9. Bode $H B$, Bethe $B$, Höfs R, Zeeck A. Big effects from small changes: possible ways to explore nature's chemical diversity. Chem Bio Chem. 2002;3(7):619-27

10. Olano C, Méndez C, Salas JA. Antitumor compounds from marine actinomycetes. Mar drugs. 2009;7(2):210-48.

11. Wadkins RM, Vladu B, Tung C-S. Actinomycin D binds to metastable hairpins in single-stranded DNA. Biochemistry. 1998;37(34):11915-23.

12. Fiedler H-P. Biosynthetic capacities of actinomycetes. 1 screening for secondary metabolites by HPLC and UV-visible absorbance spectral libraries. Nat Prod Lett. 1993;2(2):119-28.

13. Broach JR, Thorner J. High-throughput screening for drug discovery. Nature. 1996;384(6604):14-6.

14. Balagurunathan R, Radhakrishnan M. Actinomycetes: diversity and their importance. In: Trivedi PC, editor. Microbiology-applications and current trends. Jaipur: Pointer publishers; 2007. p. 297-329.

15. Baloch MA, Qureshi AA, Waheed A, Ali M, Ali N, Tufail M, et al. A study on natural radioactivity in Khewra Salt Mines, Pakistan. J Rad Res. 2012;53(3):411-21.

16. Mukku VJ, Speitling M, Laatsch $H$, Helmke E. New Butenolides from Two Marine Streptomycetes 1. J Nat Prod. 2000;63(11):1570-2.

17. Chen C, Shi R, Liu B-B, Zhang Y-J, Sun H-Z, Li C-T, et al. Halomonas qijiaojingensis sp. nov. and Halomonas flava sp. nov., two moderately halophilic bacteria isolated from a salt lake. Anton Van Leeuw. 2011;100(3):365-73.

18. Liu H, Xiao L, Wei J, Schmitz JC, Liu M, Wang C, et al. Identification of Streptomyces sp. nov. $\mathrm{WH} 26$ producing cytotoxic compounds isolated from marine solar saltern in China. World J Microbiol Biotechnol. 2013;29(7):1271-8.

19. Locci R. Streptomycetes and related genera. Berg Manal Sys Bacteriol. 1989;4:2451-508

20. Li J, Ovakim DH, Charles TC, Glick BR. An ACC deaminase minus mutant of Enterobacter cloacae UW4No longer promotes root elongation. Curr Microbiol. 2000;41(2):101-5.
21. Taddei A, Rodríguez MJ, Márquez-Vilchez E, Castelli C. Isolation and identification of Streptomyces spp. from Venezuelan soils: morphological and biochemical studies. I. Microbiol Res. 2006;161(3):222-31.

22. Mclaughlin JL. Crown gall tumours on potato discs and brine shrimp lethality: two simple bioassays for higher plant screening and fractionation. Methods Plant Biochem. 1991;6:1-32

23. Menéndez N, Nur-e-Alam M, Braña AF, Rohr J, Salas JA, Méndez C. Biosynthesis of the antitumor Chromomycin A3 in Streptomyces griseus: analysis of the gene cluster and rational design of novel Chromomycin analogs. Chem Biol. 2004;11(1):21-32

24. Rather S, Kumar S, Rah B, Arif M, Ali A, Qazi P. A potent cytotoxic metabolite from terrestrial actinomycete, Streptomyces collinus. Med Chem Res. 2014:23(1):382-7.

25. Vijayabharathi R, Bruheim P, Andreassen T, Raja DS, Devi PB, Sathyabama $\mathrm{S}$, et al. Assessment of resistomycin, as an anticancer compound isolated and characterized from Streptomyces aurantiacus AAA5. J Microbiol. 2011:49(6):920-6.

26. Yuan X, Yang R, Cao X, Gao J. Taxonomic identification of a novel strain of Streptomyces cavourensis subsp. washingtonensis, ACMA006, exhibiting antitumor and antibacteria activity. Drug Discov Ther. 2010;4(6):405-11.

27. Anibou M, Chait A, Zyad A, Taourirt M, Ouhdouch Y, Benherref A. Actinomycetes from Moroccan habitats: isolation and screening for cytotoxic activities. World J Microbiol Biotechnol. 2008;24(10):2019-25.

28. Rohr J, Méndez C, Salas JA. The biosynthesis of aureolic acid group antibiotics. Bioorg Chem. 1999;27(1):41-54.

29. Hu Y, Espindola APD, Stewart NA, Wei S, Posner BA, MacMillan JB. Chromomycin SA analogs from a marine-derived Streptomyces sp. Biorg Med Chem. 2011;19(17):5183-9.

30. Antony-Babu S, Stach JE, Goodfellow M. Genetic and phenotypic evidence for Streptomyces griseus ecovars isolated from a beach and dune sand system. Anton Van Leeuw. 2008:94(1):63-74.

31. Porter J, Robbins J, Bacon C, Himmelsbach D, Haeberer A. Determination of epimeric 1-(3-indolyl) propane-1, 2, 3-triol isolated from Balansia epichloe. Lloydia. 1977;41(1):43-9.

32. Lingens F, Lange J. Synthese von 3-[Indolyl-(3)]-glycerin und 3-[N-Methylindolyl-(3)]-glycerin. Liebigs Ann. 1970;738(1):46-53.

33. Ozaki T, Nishiyama M, Kuzuyama T. Novel tryptophan metabolism by a potential gene cluster that is widely distributed among actinomycetes. $J$ Biol Chem. 2013;288(14):9946-56.

34. Sánchez López JM, Martínez Insua M, Pérez Baz J, Fernández Puentes JL, Cañedo Hernández LM. New cytotoxic indolic metabolites from a marine Streptomyces. J Nat Prod. 2003;66(6):863-4.

35. Hayakawa M, Yoshida Y, limura Y. Selective isolation of bioactive soil actinomycetes belonging to the Streptomyces violaceusniger phenotypic cluster. J Appl Microbiol. 2004;96(5):973-81.

36. Küster E, Williams S. Selection of media for isolation of streptomycetes. Nature. 1964;202:928-9.

37. Shirling Et, Gottlieb D, editors. Method for characterization of Streptomyces species. Int J Syst. Citeseer; 1966

38. Williams S, Goodfellow M, Alderson G, Wellington E, Sneath P, Sackin M. Numerical classification of Streptomyces and related genera. J Gen Microbiol. 1983;129(6):1743-813.

39. Cavaletti L, Monciardini P, Bamonte R, Schumann P, Rohde M, Sosio M et al. New lineage of filamentous, spore-forming, gram-positive bacteria from soil. Appl Environ Microbiol. 2006;72(6):4360-9.

40. Hopwood DA, Bibb M, Kieser T, Bruton C, Kieser H, Lydiate D et al. Genetic manipulation of Streptomyces: a laboratory manual. John Innes Foundation Norwich; 1985

41. Tamura K, Dudley J, Nei M, Kumar S. MEGA4: molecular evolutionary genetics analysis (MEGA) software version 4.0. Mol Biol Evol. 2007;24(8):1596-9.

42. Solis PN, Wright CW, Anderson MM, Gupta MP, Phillipson JD. A microwell cytotoxicity assay using Artemia salina (brine shrimp). Planta Med. 1993:59(03):250-2.

43. Sajid I, Yao CBFF, Shaaban KA, Hasnain S, Laatsch H. Antifungal and antibacterial activities of indigenous Streptomyces isolates from saline farmlands: prescreening, ribotyping and metabolic diversity. World J Microbiol Biotechnol. 2009;25(4):601-10

44. Mosmann T. Rapid colorimetric assay for cellular growth and survival: application to proliferation and cytotoxicity assays. J Immunol Methods. 1983:65(1):55-63. 